Ramona A. Kearney MD FRCPC,

Jose K. Rosales MD FRCPC, William J. Howes MD FRCSC

\title{
Craniosynostosis: an assessment of blood loss and transfusion practices
}

Assessment and accurate replacement of blood loss during primary craniosynostosis repair is difficult due to patient size and surgical technique. Eighty-five charts of all patients undergoing primary craniosynostosis repair over a 15-year period were reviewed to determine blood loss and to assess blood transfusion practices both intraoperatively and postoperatively. Blood loss was calculated on the basis of estimated red cell mass (ERCM). Blood transfusion management was considered appropriate if the postoperative or posttransfusion ERCM was within 15 per cent of the preoperative value. Isolated sagittal craniectomy was the most common operation performed (60 per cent). Mean blood loss for sagittal craniectomies was 24 per cent of estimated blood volume (EBV) or approximately 20 $\mathrm{ml} \cdot \mathrm{kg}^{-1}$ and for metopic craniectomies 42 per cent of $E B V(P<$ 0.05 ). Intraoperatively, 70 per cent of all patients were appropriately managed with respect to blood transfusion. Postoperatively only 29 per cent of patients receiving transfusions were transfused appropriately. At our institution, intraoperative blood transfusion practices are appropriate, but postoperative transfusions are frequently unnecessary.

Key words

ANAESTHESIA: paediatric; SURGERY: paediatric, neurological, craniosynostosis; TRANSFUSION: stored blood.

From the Departments of Anaesthesia and Neurosurgery, Izaak Walton Killam Children's Hospital, Dalhousie University, Halifax, Nova Scotia.

Address correspondence to: Dr. R. A. Kearney, Department of Anaesthesia, The Charles A. Janeway Child Health Centre, Newfoundland Drive, St. John's, Newfoundland, A I A IR8.
The most important risk to the infant during primary craniosynostosis repair is blood loss. The assessment and accurate replacement of this loss is a major concern for the anaesthetist. There are few published estimates of blood loss for this procedure. Surgical and anaesthetic practices vary widely in attempts to reduce the loss. ${ }^{1,3}$ Fewer reports include any assessment of the anaesthetists' ability to transfuse blood in appropriate quantities. ${ }^{4}$ The difficulty in accurate determination of blood loss in these procedures often leaves the anaesthetist to rely on his experience and the stability of the patient's vital signs. This report presents the estimates of blood loss and an assessment of blood transfusion practices found in a retrospective study of patients undergoing operations for primary craniosynostosis during a 15-year period.

\section{Methods}

From October, 1970, to March, 1986, 85 operations for primary craniosynostosis were performed on 80 patients at the Izaak Walton Killam Hospital for Children in Halifax, Nova Scotia. Charts of these patients were reviewed with respect to the patients' age and weight, perinatal history, associated anomalies, cranial suture involvement, all haemoglobin ( $\mathrm{Hb})$, haematocrit (Hct) and platelet counts recorded, duration of surgery and anaesthesia, surgical procedure performed, type, quantity and timing of blood products transfused, and perioperative complications. All blood samples for determination of Hct are collected by microsampling in this hospital and have been so for the duration of the study.

Blood loss was calculated on the basis of estimated red cell mass (ERCM) given that

ERCM = estimated blood volume $(\mathrm{EBV}) \times \frac{\mathrm{Hct}}{100}$,

and

$\mathrm{ERCM}_{(\mathrm{a})}+\mathrm{ERCM}_{(\mathrm{b})}-\mathrm{ERCM}_{(\mathrm{c})}=\mathrm{ERCM}_{\text {(deficit) }}{ }^{5,6}$

Where (a) = pretransfusion, (b) = transfused, (c) = posttransfusion.

The EBV was estimated at $80 \mathrm{ml} \cdot \mathrm{kg}^{-1}$ for pretrans- 
fusion and posttransfusion values. ${ }^{7}$ The value of Hct for $\mathrm{ERCM}_{\text {transfused }}$ was 0.40 for whole blood and reconstituted packed red blood cells with plasma and 0.75 for packed red blood cells given alone ${ }^{8,9}$ The calculated ERCM $_{\text {deficit }}$ was converted to per cent preoperative blood volume.

Management was considered appropriate if the postoperative ERCM was within 15 per cent of the preoperative value. As the normal value for Hct in this age group is $0.36 \pm 0.051 . / 1 .,^{10}$ a 15 per cent decrease in the volume of packed red blood cells is an Het value of 0.30 which is commonly considered the minimal acceptable intraoperative Hct. ${ }^{6}$

Controlled hypotension or scalp infiltration with local anaesthetics containing epinephrine were not used during any of the surgical procedures. Intraoperative monitoring techniques did not include invasive methods. Heart rate, auscultation of heart sounds and breath sounds, temperature, non-invasive blood pressure, and in the later years, pulse oximetry and end-tidal $\mathrm{CO}_{2}$ were the monitors used. Both intraoperative and postoperative transfusion managements were assessed. Only those patients who received blood transfusions in the postoperative period were considered. Management was considered appropriate if certain indications for transfusion were present and if so, following transfusion the ERCM was within 15 per cent of the preoperative value. The indications for transfusion were considered to be: postoperative Hct < 0.30 , unstable vital signs and evidence of continued bleeding.

Means for various measurements were compared using Student's $\mathrm{t}$ test for unpaired samples.

\section{Results}

Eight charts contained insufficient data for analysis and one chart was missing. Seventy-six operations on 73 patients were reviewed. Of the three patients who underwent a second operation, one had surgery initially for sagittal synostosis followed two weeks later by surgery for bicoronal involvement. The other two patients

TABLE I Distribution of inyolved sutures

\begin{tabular}{lc}
\hline Suture & Number of Cases \\
\hline Sagittal & 46 \\
Unicoronal & 13 \\
Metopic & 5 \\
Bicoronal & 6 \\
Sagittal + lambdoid & 2 \\
Sagittal + coronal & 1 \\
Coronal + squamosal & 1 \\
Bicoronal + metopic & 1 \\
Sagintal + lambdoid + coronal & 1 \\
& -76 \\
\hline
\end{tabular}

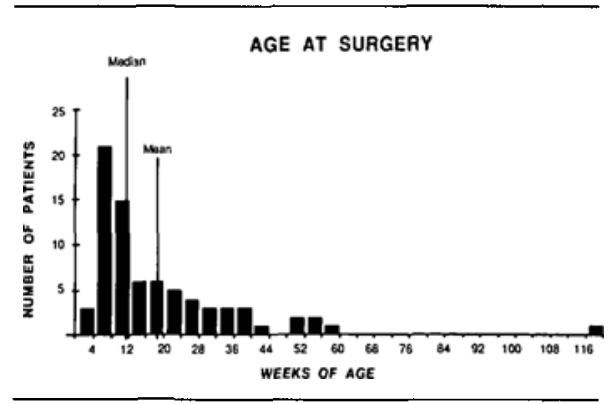

FIGURE Age at surgery.

had repeat operations on the same suture four months apart (one sagittal and one unicoronal, respectively). Sixty per cent of all operations were performed for isolated sagittal synostosis. Involvement of one or both coronal sutures was next in frequency at 25 per cent, followed by metopic suture involvement at seven per cent (Table I). Fifteen patients ( 21 per cent) had other congenital anomalies. There was a higher incidence of these anomalies among patients with multiple suture involvement compared with single suture involvement (42 per cent vs 16 per cent) (Table II).

The mean weight of patients at operation was $6.5 \mathrm{~kg}$ (range $2.7-11.7 \mathrm{~kg}$ ). The male to female ratio was approximately 2:1. Age distribution is shown in the Figure; mean age was 19.2 weeks, median age was 11.5 weeks.

Incomplete charting prevented determination of the surgical duration in nine operations (four sagittal, two unicoronal, one bicoronal, one metopic, one coronal + squamosal). Table III shows the mean duration of the remainder. At our institution the operation for isolated sagittal synostosis was revised during this time period from a standard linear craniectomy, to a linear craniectomy with excision and closure of bilateral parietal

TABLE II Congenital anomalies and associated synostotic sutures

\begin{tabular}{lll}
\hline Anamaly & Surure & $\begin{array}{l}\text { Number of } \\
\text { patients }\end{array}$ \\
\hline Crouzon syndrome & Bicoronal & 3 \\
Pfeiffer syndrome & Unicoronal & 1 \\
Carpenter syndrome & Sagittal & 2 \\
Apert syndrome & Bicoronal & 1 \\
Hydrocephalus & 1 metopic/l unicoronal & 2 \\
Syndactyly of foot & Metopic & 1 \\
Cleft lip and palate & Sagittal + Coronal & 1 \\
Congenital heart disease & Sagittal & 1 \\
Bilateral inguinal herniae & Sagittal & 1 \\
Bilateral rectus palsy & Unicoronal & 1 \\
\hline
\end{tabular}


TABLE III Duration of surgery

\begin{tabular}{lr}
\hline Suture & Mean duration in minutes $( \pm S D)$ \\
\hline Sagittal & $74 \pm 26$ \\
Unicoronal & $105 \pm 26$ \\
Metopic & $78 \pm 19$ \\
Bicoronal & $135 \pm 30$ \\
Others & $91 \pm 39$ \\
\hline
\end{tabular}

TABLE IV Blood loss (per cent EBV)

\begin{tabular}{ll}
\hline Suture & Blood loss (mean $\pm S D$ ) \\
\hline Sagittal & $24.1 \pm 14.7$ \\
Unicoronal & $20.9=11.9$ \\
Metopic & $42.0 \pm 12.0$ \\
Bicoronal & $64.7 \pm 35.2$ \\
Others & $22.9 \pm 16.1$ \\
\hline
\end{tabular}

wedges. When blood loss was assessed for the two operations separately it was found that the earlier operation had a mean loss of 21 per cent of the EBV and the later operation had a mean loss of 28 per cent with surgical durations of 82 minutes and 59 minutes respectively (NS). As these differences were not significant the measurements were combined to give a mean blood loss of 24 per cent of the EBV which represents a loss of $19 \pm$ $11 \mathrm{ml} \cdot \mathrm{kg}^{-1}$ (mean $\pm \mathrm{SD}$ ), or approximately $20 \mathrm{ml} \cdot \mathrm{kg}^{-1}$ (Table IV). The mean operating time for all sagittal craniectomies was 70 minutes. For unicoronal cranjectomies, despite a similar mean blood loss of 21 per cent, the mean operating time was 57 per cent higher $(\mathrm{P}<0.01)$ (Table IV). For metopic craniectomies, the operating time was similar to that for sagittal craniectomies, but the mean blood loss was almost double, 42 per cent $v s 24$ per cent ( $P$ $<0.02$ ). For multiple suture involvement, if both coronal sutures were involved, blood loss was much higher than that associated with other suture combinations ( 62 per cent vs 18 per cent).

According to our criteria of a 15 per cent or less deviation from the preoperative red cell mass, management was appropriate intraoperatively in 70 per cent of the cases (Table V). Postoperatively, 21 patients received transfusions. In one third of these the earlier indications for transfusions were not present. Only 29 per cent ( $6 / 21)$ met the criteria for appropriate transfusion management.

TABLE V Results of intraoperative transfusion management

\begin{tabular}{ll}
\hline $\begin{array}{l}\text { Postoperative ERCM as per cent of } \\
\text { preoperative ERCM }\end{array}$ & $n=76$ \\
\hline$>115 \%$ & $14(18 \%)$ \\
$85-115 \%$ & $53(70 \%)$ \\
$585 \%$ & $9(12 \%)$ \\
\hline
\end{tabular}

\section{Discussion}

With an incidence of $0.4-1.0$ per 1000 live births, craniosynostosis is a relatively common congenital disorder. ${ }^{11}$ Most paediatric anaesthetists are familiar with the surgical management of this deformity. Although premature closure of the sagittal suture alone is the most common manifestation, other sutures, singly or in combination, may be involved. ${ }^{12}$

The relationship of craniosynostosis to neurological deficit and hydrocephalus is not clear. There appears to be general agreement that total synostosis (cloverleaf skull) may cause elevation of intracranial pressure during the rapid brain growth periods. In the situation of single suture involvement, however, the effect on the brain is uncertain. It is felt by many that the goal of operative management is primarily cosmetic. "The best result is achieved when surgery is performed at an early age and it has been recommended that the operation be performed before three months of age and even at four to six weeks of age. ${ }^{12,13}$ For this operation the anaesthetic considerations include large rapid blood loss, blood transfusion, airway maintenance despite lack of access to the face and patient positioning which frequently includes the prone position. ${ }^{14}$

Assessment of blood loss in neurosurgery has always been difficult. Diligent efforts to weigh sponges, use graduated suction cylinders and colourimetric methods to measure haemoglobin concentration may be inadequate for the paediatric patient. An important portion of their small blood volumes forms unmeasureable stains on surgical gowns and drapes. Irrigating fluid and cerebrospinal fluid alter sponge weight and suction trap volume. For craniosynostosis surgery, simple repairs entail relatively short operating times; $20-50$ per cent of the patient's blood volume may be lost in 30 minutes. Inaccurate estimates of blood loss may result in transfusions of either inadequate or excessive volumes of blood.

Several factors influence the amount of blood lost during this procedure. These include controlled ventilation, induced hypotension, scalp infiltration and haemostatic scalp sutures. As the periosteum and not the scalp is the major source of blood loss, ${ }^{1}$ the usefulness of scalp infiltration with local anaesthetic solutions containing epinephrine $e^{2,3}$ may not be justified, but this has not been assessed by controlled studies. A decrease in blood loss with controlled ventilation has been shown in other neurosurgical procedures performed with the patient in the prone position. ${ }^{15}$ Hypotensive anaesthesia has been examined by several authors using inhalation anaesthesia ${ }^{4}$ or ganglion blockade. ${ }^{16}$ Only one of these was addressed specifically to patients undergoing craniectomy for craniosynostosis. ${ }^{4} \mathrm{~A}$ reduction in blood loss was shown with controlled hypotension but the amount was of doubtful 
importance and therefore does not justify the risks of the technique.

Factors examined in this review include the suture or sutures involved, the surgical duration and the operative procedure performed. With single suture involvement, the amount of blood loss correlated better with the suture involved than with the operating time. The blood loss was not significantly different between the two operations for sagittal craniectomies.

Our figures for blood loss are in keeping with other studies. In terms of estimated blood volume, the mean blood loss for linear craniectomies has been reported to be approximately 20 per cent ${ }^{4}$ and 40 per cent. ${ }^{3}$ Reports of blood loss for bicoronal and multiple suture involvement are found in only one study based on only two patients. No comparisons can be made with this data.

The results of perioperative transfusions reveal that despite the difficulty of intraoperative assessment of blood loss, empirical transfusion practices are adequate for most patients. It is difficult to determine to what aspect of management we owe our results. Invasive monitoring has been used more frequently in this population in recent years to improve intraoperative fluid management. We do not feel the results of this study justify changing our practices. Routine use of invasive monitoring with its inherent complications is not warranted in patients with simple craniosynostosis who currently do well and suffer no significant perioperative complications. Close observation of intraoperative losses and communication with the neurosurgeon are important factors determining our results.

In terms of blood replacement, a Hct of 0.30 remains a reasonable postoperative goal and to that end we recommend an allowable blood loss to a Het of 0.30 with crystalloid replacement solutions. Further blood loss should be replaced with packed red blood cells. We have determined that mean blood losses of approximately 24 , 40 , and 65 per cent of EBV occur for sagittal or unicoronal, metopic and bicoronal craniectomies respectively. Knowledge of these figures and the preoperative Hct allow the expected volume of blood transfusion to be calculated before surgery to aim for a postoperative Hct of 0.30 . Transfusion of this volume should begin when the skin incision is made. Additional volume can be given as indicated by intraoperative assessment. This should enable one to manage blood transfusions more accurately in these patients.

It is disturbing to note that postoperatively, in the absence of acute blood loss and in the presence of repeat Het determinations, transfusion practices are poor. One explanation for the unnecessary transfusions may lie in the concern over postoperative haematoma formation and further blood loss. Only three patients in this study had significant blood loss more than 24 hours postoperatively. In no case was this a precipitous drop in Het and prophylactic transfusion would not have been required. Another explanation may be that neurosurgical housestaff, unfamiliar with normal values for Hct and blood volume in infants, may order arbitrary volumes of blood instead of calculating the required amount with the goal of achieving a specific Het which would be appropriate for that child.

In summary, blood loss during craniectomy for primary craniosynostosis is significant. A variety of factors influences the degree of blood loss but, due to the diversity in the surgical approach to synostosis surgery, our figures reflect only local practice. Meticulous attempts at monitoring blood loss despite its inherent difficulties are necessary. At our institution, intraoperative blood transfusion management for this procedure was performed appropriately for the majority of patients. Postoperative transfusion management merits greater attention. Normal Het values for age, determination of an acceptable postoperative Hct and the patient's vital signs must be considered carefully to avoid unnecessary blood transfusions and the hazards that may ensue.

\section{References}

1 Hans $J F$, Trusso R, Levy WJ. Craniosynostectomy with reduced blood loss. Neurosurgery 1981; 8: 20911.

2 Albright AL. Operative normalization of skull shape in sagittal synostosis. Neurosurgery 1985; 17: 329-31.

3 Scholtes $J L$. Craniofaciosynostosis: anaesthetic and perioperative management. Acta Anaesth Belg 1985; 3 : 176-85.

4 Diaz $J H$, Lockhart $C H$. Hypotensive anaesthesia for craniectomy in infancy. Br J Anaesth 1979; 51: 233-5.

5 Furman EB, Roman DG, Lemmer LA, Hairabet J, Jasinska $M$, Laver $M B$. Specific therapy in water, electrolyte and blood-volume replacement during pediatric surgery. Anesthesiology 1975; 42: 187-93.

6 Lockhart $\mathrm{CH}$. Maintenance of general anaesthesia. In: Gregory GA (Ed.). Pediatric Anesthesia. New York, Churchill Livingstone, 1983; 463-80.

7 Smith RM. Anaesthesia for Infants and Children. 4th ed. St. Louis: The C.V. Mosby Company, 1980: 553.

8 Miller RD, Brzica SM. Blood, blood component, colloid, and autotransfusion therapy. In: Miller RD (Ed.). Anesthesia. New York: Churchill Livingstone, 1981: 885-922.

9 Cohen MM. Craniosynostosis - diagnosis, evaluation and management. New York: Raven Press, 1986: 21, 252.

10 Nelson WE. Textbook of Pediatrics. 11 th ed. Philadelphia: W.B. Saunders Company, 1979: 1367. 
11 Blojchman MA, Shepherd FA, Perrault RA. Clinical use of blood, blood components and blood products. Can Med Assoc J 1979; 121: 33-42.

12 Shillito J, Matson DD. Craniosynostosis: a review of 519 surgical patients. Pediatrics 1968; 41: 829-53.

13 Anderson FM, Griger $L$. Craniosynostosis - a survey of 204 cases. J Neurosurg 1965; 22: 229-40.

14 Rosales $J K$, Hannallah RS. Anaesthesia for pediatric neurological surgery. Int Anesth Clinics 1977; 15: 265-81.

15 Meridy HW, Creighton RE, Humphreys RP. Complications during neurosurgery in the prone position in children. Can Anaesth Soc J 1974; 21: 445-53.

16 Salem MR, Wong AY, Bennett EJ, Mani M. Deliberate hypotension in infants and children. Anesth Analg 1974; 53: 975-81.

\section{Résumé}

La technique chirurgicale et la taille des patients rendent difficiles l'évaluation et le remplacement des pertes sanguines lors d' une primo-correction de craniosynostose. Nous avons revise 85 dossiers s'échelonnant sur 15 ans, afin d'évaluer les pertes sanguines et leur remplacement par transfusion de sang pendant et après ce type d'intervention. Les pertes étaient calculés en fonction d'un estimé de la masse des globules rouges (MGRE) et pour qualifier d' adéquat le remplacement, la MGRE post-opératoire ou post-transfusion devait être égale d̀ la valeur pré-opératoire à 15 pour cent près. Pour les craniectomies sagittales isolées, pratiquées dans 60 pour cent des cas, les pertes équivalaient en moyenne à 24 pour cent du volume sanguin estime (VSE) soit approximativement $20 \mathrm{ml}$. $\mathrm{kg}^{-1}$, alors que 42 pour cent du VSE etait perdu avec les craniectomies métopiques $(P<0.05)$. Pendant la période per-opératoire, 70 pour cent des patients étaient transfusés de façon adéquate, mais seulement 29 pour cent l'étaient en période post-opératoire. Ainsi, dans notre milieu, la pratique de transfusion intra-opératoire est satisfaisante mais plusieurs transfusions sanguines post-opératoires sont injustifiees. 